\title{
OPEN Photo-oxidative degradation of polyacids derived ceria nanoparticle modulation for chemical mechanical polishing
}

\author{
Eungchul Kim ${ }^{1}$, Jiah Hong ${ }^{1}$, Hyunho Seok ${ }^{2}$ \& Taesung Kim ${ }^{1,2 \bowtie}$
}

The effects of photo-oxidative degradation of polyacids at various concentrations and with different durations of ultraviolet (UV) irradiation on the photo-reduction of ceria nanoparticles were investigated. The effect of UV-treated ceria on the performance of chemical mechanical polishing (CMP) for the dielectric layer was also evaluated. When the polyacids were exposed to UV light, they underwent photo-oxidation with consumption of the dissolved oxygen in slurry. UV-treated ceria particles formed oxygen vacancies by absorbing photon energy, resulting in increased $\mathrm{Ce}^{3+}$ ions concentration on the surface, and when the oxygen level of the solution was lowered by the photooxidation of polymers, the formation of $\mathrm{Ce}^{3+}$ ions was promoted from 14.2 to $36.5 \%$. Furthermore, chain scissions of polymers occurred during the oxidation process, and polyacids with lower molecular weights were found to be effective in ceria particle dispersion in terms of the decrease in the mean diameter and size distribution maintaining under 0.1 of polydispersity index. With increasing polyacid concentration and UV irradiation time, the $\mathrm{Ce}^{3+}$ concentration and the dispersity of ceria both increased due to the photo-oxidative degradation of the polymer; this enhanced the CMP performance in terms of $87 \%$ improved material removal rate and $48 \%$ lowered wafer surface roughness.

Chemical mechanical polishing (CMP) is an effective technique to achieve local and global planarization of semiconductor wafers for the development of next-generation devices. With recent developments in threedimensional integrated circuits of semiconductor devices, such as NAND flash memory, the number of vertically stacked gates has significantly increased and larger step heights are encountered ${ }^{1-3}$. Therefore, it is crucial to meet the requirements of a high oxide removal rate to overcome these new challenges for the CMP process. Ceria is known to exhibit a high oxide removal rate due to its strong chemical interaction with an oxide surface ${ }^{4,5}$. Cook first proposed the "chemical tooth" model to explain the removal mechanism of ceria abrasives used to obtain a high polishing efficiency for glass substrates ${ }^{6}$. Several mechanisms for the same have been suggested by many different researchers ${ }^{7-9}$ and it is widely known that active sites for reactions consist of $\mathrm{Ce}^{3+}$ ions on the ceria surfaces ${ }^{10-12}$. The formation of an oxygen vacancy results in the reduction of cerium ions in the lattice from $\mathrm{Ce}^{4+}$ to $\mathrm{Ce}^{3+13-15}$. $\mathrm{Ce}^{3+}$ plays a vital role in determining the reaction with the oxide surface, forming strong Ce-O-Si bonds ${ }^{16-18}$. It has been reported that a higher surface concentration of $\mathrm{Ce}^{3+}$ ions leads to a higher removal rate of the $\mathrm{SiO}_{2}$ layer due to the strong interaction between ceria and $\mathrm{SiO}_{2}{ }^{19,20}$. Several studies have been conducted to improve the oxide removal efficiency by increasing the $\mathrm{Ce}^{3+}$ concentration in ceria abrasives. Kim et al. investigated the effect of the concentration of $\mathrm{Ce}^{3+}$ ions on the removal rate of $\mathrm{SiO}_{2}$ layers and reported a method to synthesize ceria particles with a high concentration of $\mathrm{Ce}^{3+}$ ions by reducing the primary particle size ${ }^{21}$. Wang et al. found that the ratio of $\mathrm{Ce}^{3+}$ to $\mathrm{Ce}^{4+}$ ions on the abrasive surface increases with decreasing concentration of ceria slurry, which results in improved removal rates in optical glass CMP ${ }^{22}$. Various approaches have been proposed to enhance the catalytic activity of ceria by promoting surface oxygen vacancy formation. Several studies have shown that doping metal ions into $\mathrm{CeO}_{2}$ lattice results in superior catalytic performance by lowering the oxygen vacancy formation energy required to detach an oxygen atom from the surface ${ }^{23,24}$. Previously, we demonstrated that UV light irradiation can generate a large number of oxygen vacancy defects and increase the $\mathrm{Ce}^{3+}$ concentration, leading to an effective reduction of ceria ${ }^{25}$. It is known that ambient oxygen level promotes a reoxidation process of ceria, in other words, inhibits the reduction reaction of ceria ${ }^{26}$. Therefore, a low oxygen

${ }^{1}$ School of Mechanical Engineering, Sungkyunkwan University, Suwon 16419, South Korea. ${ }^{2}$ SKKU Advanced Institute of Nanotechnology (SAINT), Sungkyunkwan University, Suwon 16419, South Korea. ${ }^{\square}$ email: tkim@ skku.edu 
level is highly desirable for enhanced oxygen vacancy formation because this condition prevents the reoxidation of ceria particles by oxygen in the ambient environment.

In this study, photo-oxidative degradation of polymers was adopted to lower the oxygen level in ceria slurry. A few water-soluble polymer chains undergo photo-oxidative reactions under the exposure of UV light, which leads to chain scission ${ }^{27}$. Polyacids used as dispersing agents in ceria slurries, such as poly(acrylic acid) (PAA) and poly(methacrylic acid) (PMA), are degraded under the exposure of UV light and a low-oxygen environment is achieved by the photo-oxidation process. In addition, the degraded polymers with low molecular weights increase the interaction between particles. Therefore, this improves the dispersibility of ceria particles.

Herein we propose a new strategy to improve the oxide CMP performance by photo-degradation of polyacids, which accelerates oxygen vacancy formation of ceria abrasives under UV-light irradiation. The photocatalytic degradation behavior of polymers in ceria slurry was studied, and its effect on the concentration of $\mathrm{Ce}^{3+}$ ions and CMP performance was evaluated.

\section{Results and discussion}

Photo-oxidation of polyacids. UV light enhances the physical reactivity of ceria. UV light reduces ceria by forming oxygen vacancies on its surface. The oxygen vacancy formation energy on the ceria surface is $1.16 \mathrm{eV}$ and the separation of the electron-hole pair upon UV light irradiation decreases the oxygen vacancy formation energy to a negative value $(-0.64 \mathrm{eV})^{28,29}$. Therefore, UV light irradiation on the ceria is directly involved in the creation of oxygen vacancy. The electrons and holes generated from the UV irradiation reduce $\mathrm{Ce}^{4+}$ to $\mathrm{Ce}^{3+}$ and the holes oxidize oxygen anions. Since ceria releases oxygen in the process of reduction, it should be reacted at a low oxygen level to efficiently reduce ceria ${ }^{26}$. Since dissolved oxygen can oxidize ceria, the process of removing dissolved oxygen is necessary to prevent reoxidation of ceria by extracted oxygen from $\mathrm{it}^{30}$. In this experiment, the photo-oxidation reaction of polyacids including PAA and PMA was induced to remove dissolved oxygen during the reduction of ceria by UV irradiation. PAA and PMA are anionic surfactants with negatively charged carboxylic groups in the main chain and are commonly used as dispersants to enhance the dispersibility of particles upon adsorption to ceria surfaces with positive potential in acidic media ${ }^{31-35}$. Polyacids undergo photooxidation and photo-degradation when exposed to oxygen and UV light. UV irradiation on polyacids causes cleavage of chemical bonds in main chains and side-groups, as shown in the following Reactions $(1-3)^{36-38}$.

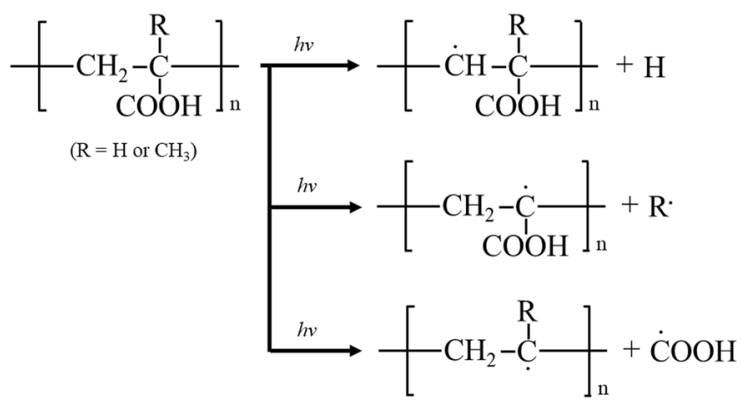

$$
\mathrm{P}^{*}+\mathrm{O}_{2} \stackrel{\mathrm{hv}}{\rightarrow} \text { POO }^{*}
$$

The same macroradicals are created in PMA and PAA. Following photo-oxidation causes the polymer chains to break, and this is known as chain scission ${ }^{39-41}$. In the presence of oxygen, polyacids exposed to UV light react with oxygen to form macroperoxyradicals as shown in Reaction $(4)^{42}$.

Macroperoxyradicals can be propagated in a series of reactions that follow free radical mechanisms ${ }^{38}$. In general, the photooxidative degradation of polymers follows the Reactions (5-9) with chain scission ${ }^{43}$.

$$
\begin{gathered}
\mathrm{POO}^{*}+\mathrm{PH} \stackrel{\mathrm{hv}}{\rightarrow} \mathrm{POOH}+\mathrm{P}^{*} \\
\mathrm{POOH} \rightarrow \mathrm{PO}^{*}+\mathrm{HO}^{*} \\
2 \mathrm{POOH} \rightarrow \mathrm{POO}^{*}+\mathrm{PO}^{*}+\mathrm{H}_{2} \mathrm{O} \\
\mathrm{PO}^{*}+\mathrm{PH} \rightarrow \mathrm{POH}+\mathrm{P}^{*} \\
\mathrm{HO}^{*}+\mathrm{PH} \rightarrow \mathrm{H}_{2} \mathrm{O}+\mathrm{P}^{*}
\end{gathered}
$$

This process can be repeated in a loop, as shown in Figure 1a, until the energy is continuously applied, and the amount of material is sufficient. The formation of $\mathrm{HO}^{\star}$ radical during UV irradiation is very efficient, and it is the main reason for the accelerated decomposition of both polymers ${ }^{38,42,43}$. The radicals formed during polymer degradation can be terminated by various mixtures containing different functional groups, such as aldehyde, ketone, ester, peracid, alcohol, peroxide, and double bonds. 


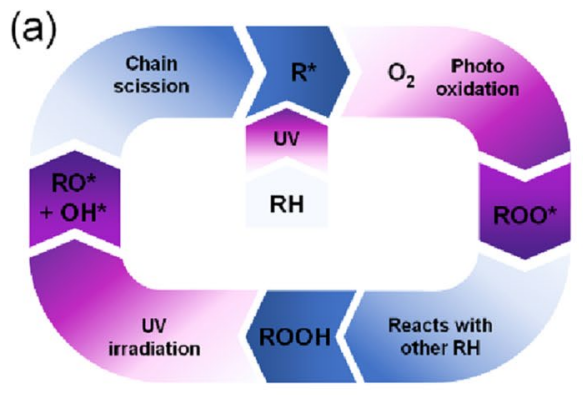

(c)

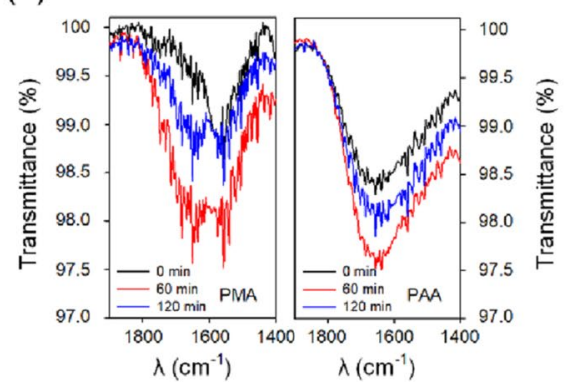

(b)

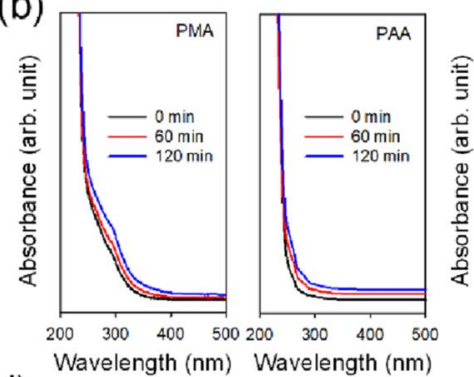

(d)

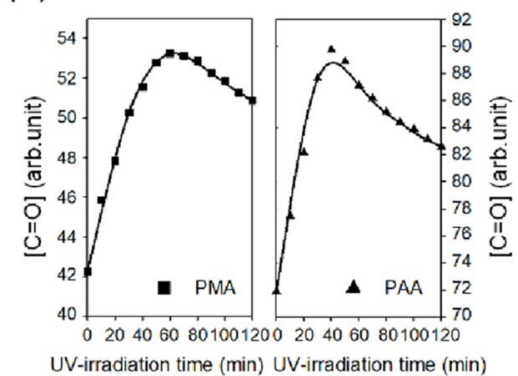

(e)
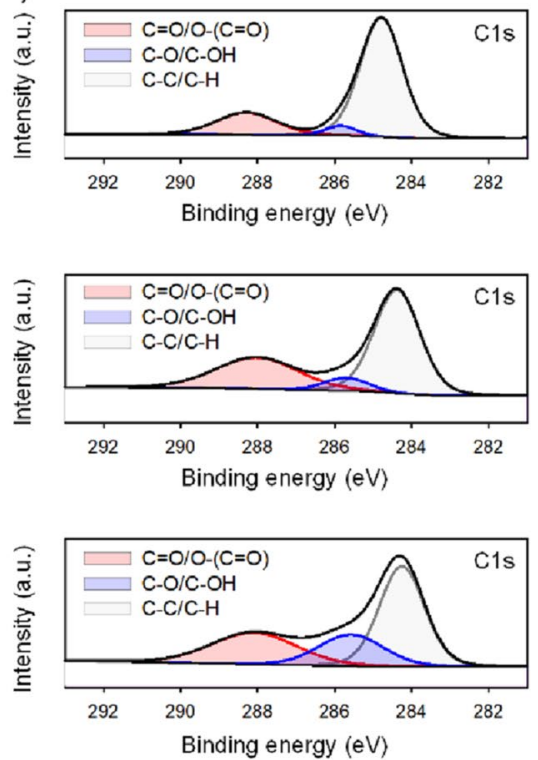

Figure 1. (a) General oxidation and photo-oxidation cycle of polymers. (b) Absorbance spectra and (c) FTIR spectrum of UV irradiated PMA (left) and PAA (right) by the UV irradiation time; 0, 60, and 120 min. (d) Changes in integral intensity of carbonyl band $\left(1707 \mathrm{~cm}^{-1}\right)$ during UV irradiation for $120 \mathrm{~min}$. (e) XPS spectra of PAA according to UV irradiation time; (top) $0 \mathrm{~min}$, (middle) $60 \mathrm{~min}$, and (bottom) $120 \mathrm{~min}$. The peak at $288.2 \mathrm{eV}$ is a $\mathrm{C}=\mathrm{O}$ bonding and the $285.8 \mathrm{eV}$ peak indicates $\mathrm{C}-\mathrm{O}$ bonding. The peak at $284.4 \mathrm{eV}$ is corresponding to $\mathrm{C}-\mathrm{C}$ and $\mathrm{C}-\mathrm{H}$ of the polymer chain ${ }^{47-49}$.

The absorption spectra of chromophores containing ethylene bonds and carbonyl groups, which were produced by the photo-oxidative degradation of polyacids, depend on their concentrations. Figure $1 \mathrm{~b}$ shows an increase in the absorbance at 280 and $300 \mathrm{~nm}$ due to chromophore formation in UV-irradiated PMA and PAA with increasing duration of irradiation, implying that the photoreaction of polyacids was accelerated with increasing duration of UV irradiation ${ }^{44-46}$.

The photo-oxidation processes were monitored by FTIR spectroscopy. Owing to the high absorption capacity of water by polyacids, the band in the hydroxy group $\left(3000-3600 \mathrm{~cm}^{-1}\right)$ was not considered. A significant peak at $1707 \mathrm{~cm}^{-1}$ was observed, which attributed to the $\mathrm{C}=\mathrm{O}$ stretching vibration of the carbonyl group, as shown in Fig. 1c. The carbonyl band of polyacids verifies photo-oxidative degradation. The integral intensity of carbonyl groups increases rapidly and decreased gradually when the number of carbonyl groups reached a maximum value, as shown in Fig. 1d. The change in maximum absorbance of a carbonyl group with increasing duration of UV irradiation shows that an opposite reaction occurred, which involved the destruction of carboxylic groups and oxidation of macro-chain. At the beginning of UV irradiation, several new carbonyl groups were formed by the photo-oxidation process, leading to a rapid increase in intensity. However, it decreased slightly due to the decomposition of carboxyl groups as the dissolved oxygen levels were lowered and chain scission was promoted by the macroperoxyradical. According to the XPS spectra shown in Fig. 1e, most of the chromophores formed from photo-oxidation of polyacids are defined as $\mathrm{C}=\mathrm{O}$ bonds of a carbonyl group along with FTIR results. In the case of the pristine PAA, the majority of peaks exist for $\mathrm{C}-\mathrm{C}$ and $\mathrm{C}-\mathrm{H}$ of the chain backbone and $\mathrm{C}=\mathrm{O}$ bonding contained in some carboxyl groups ${ }^{47}$. In the PAA subjected to $\mathrm{UV}$ treatment for $60 \mathrm{~min}$, the ratio of $\mathrm{C}=\mathrm{O}$ bonding from the carbonyl group increased due to oxidation, and at the same time, the $\mathrm{C}-\mathrm{O}$ bands slightly increased due to hydroxyl group and alkoxy radicals generated during the degradation process ${ }^{48,49}$. After 120 min, because the degradation process is promoted compared to the oxidation process, the intensity of $\mathrm{C}-\mathrm{O}$ bands increases significantly with a slight decrease in the portion of the $\mathrm{C}=\mathrm{O}$ peak. Detailed atomic concentration for each bonding with different UV irradiation times is listed in Table S1.

Photo oxidative reaction in ceria slurry and its impact on CMP. $\mathrm{CeO}_{2}$-based materials have attracted considerable attention for applications in heterogeneous catalysis due to their excellent oxygen exchange capability, related to a facile exchange between $\mathrm{Ce}^{3+}$ and $\mathrm{Ce}^{4+}$ ions ${ }^{50-52}$. During UV irradiation, ceria provides $\mathrm{O}^{\prime}$ radical with the formation of oxygen vacancy to facilitate the oxidation process of polymers ${ }^{53}$. This mechanism involves two methods for polymer oxidation. The first uses $\mathrm{O}$ ' obtained from the formation of oxygen vacancy on the surface of a ceria particle and the second is consuming dissolved oxygen in the solution by using ceria particle as a catalyst. These methods are simultaneous, and consumption of oxygen further promotes the formation of oxygen vacancy in ceria, resulting in a virtuous cycle that promotes photo-oxidative degradation of polymers.

Figure 2 a shows the IR spectra of ceria slurry containing PMA and PAA recorded after different UV irradiation times. The absorbance of the carbonyl band increased significantly because the ceria particles accelerated the photo-oxidation reaction of polyacids. A solution containing only polyacids exhibited the highest absorbance 
(a)

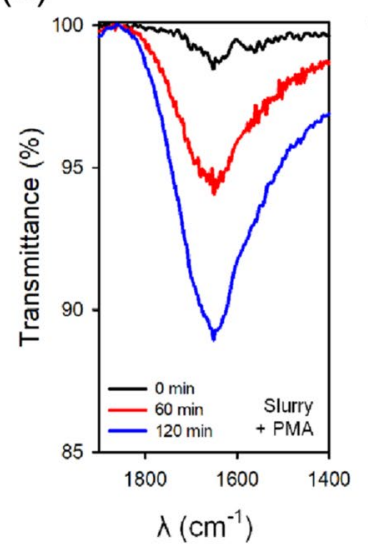

(b)

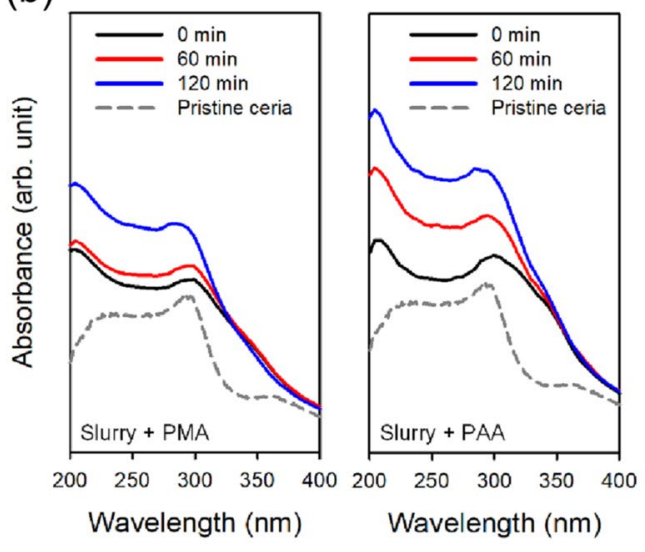

(c)
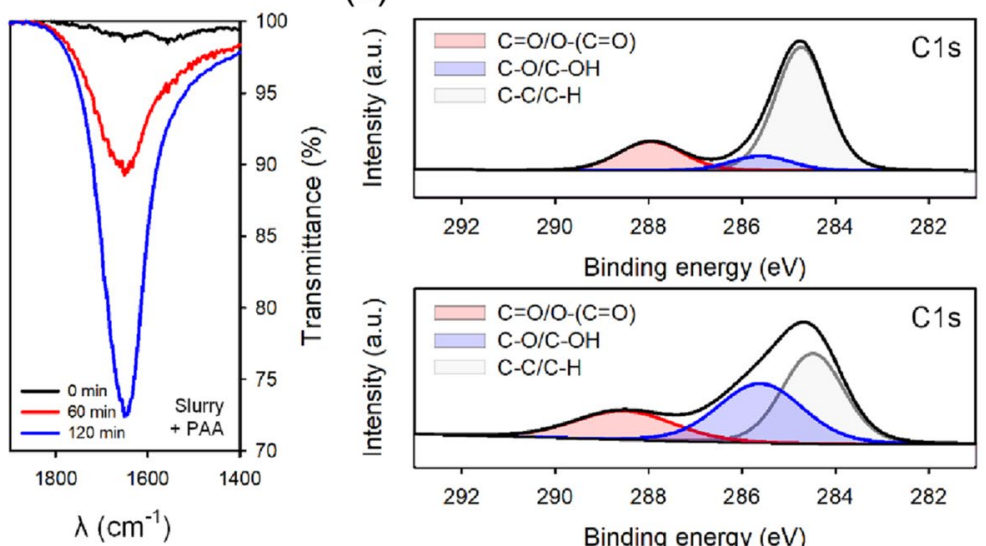

Binding energy $(\mathrm{eV})$


(

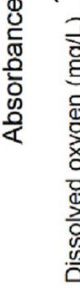

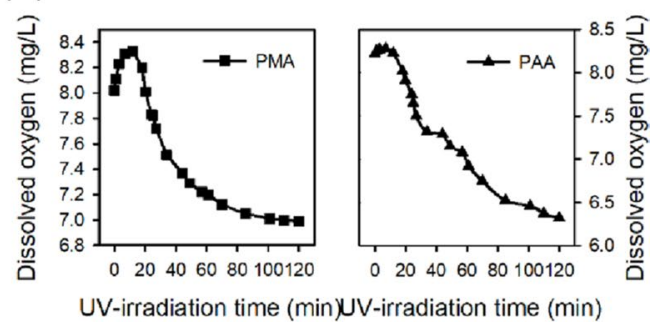

Figure 2. (a) Changes in FTIR spectrum of carbonyl band and (b) absorbance spectra of ceria slurry with 0.1 wt.\% of PMA (left) and PAA (right) during UV-irradiation for $120 \mathrm{~min}$. (c) XPS spectra of ceria slurry with $0.1 \mathrm{wt} . \%$ of PAA according to UV irradiation time; (top) $0 \mathrm{~min}$, (middle) $60 \mathrm{~min}$, and (bottom) $120 \mathrm{~min}$. (d) Changes in dissolved oxygen during UV irradiation on fabricated ceria slurry for $120 \mathrm{~min}$.

at the beginning of UV irradiation (60 min for PMA and 40 min for PAA). However, a slurry containing ceria nanoparticles showed a further increase in absorbance after UV irradiation for $2 \mathrm{~h}$. This is because the catalytic activity of ceria promoted the photo-oxidation of polyacids, leading to the continuous formation of new types of carbonyl groups in the polymer. UV-vis spectra provide information on the oxidation states of metal ions in a solution. Since the $\mathrm{Ce}^{3+}$ and $\mathrm{Ce}^{4+}$ ions have absorbance at a different wavelength, the changes in absorbance for each UV region indicate a change in the surface oxidation state of ceria particles ${ }^{52}$. The absorption peaks at 290 and $360 \mathrm{~nm}$ are ascribed to $\mathrm{Ce}^{3+}$ and $\mathrm{Ce}^{4+}$, respectively ${ }^{51,54}$. Figure $2 \mathrm{~b}$ shows the change in the absorption spectra of ceria slurry with polyacids by UV irradiation. There is no significant change in the absorption peak at $360 \mathrm{~nm}$ was observed, however, the peak at $290 \mathrm{~nm}$ drastically increased with increasing duration of UV irradiation. In company with each increase in absorbance of polyacids and pristine ceria according to UV irradiation as shown in Fig. $1 \mathrm{~b}$ and Figure S1, the significant increase in absorbance under $300 \mathrm{~nm}$ demonstrates that the formation of the chromophore and $\mathrm{Ce}^{3+}$ ions was promoted through UV irradiation. The difference in absorption spectra was not observed only by mixing the polymer in the ceria slurry without UV light, therefore, no chemical reactions or bonds between them occurred in the absence of external energy as shown in Figure S2. Figure 2c shows the $\mathrm{C} 1 \mathrm{~s}$ peak of PAA contained in the ceria slurry according to each 0,60 , and 120 min of UV irradiation time. When UV light was irradiated on the PAA added in ceria slurry, $\mathrm{C}=\mathrm{O}$ and $\mathrm{C}-\mathrm{O}$ were produced at higher rates than that of the only PAA with UV irradiation as listed in Table S2. Comparing to XPS spectra of UV irradiated PAA, the ceria nanoparticles played a significant photocatalytic role to promote the photo-oxidative degradation of polyacids. Therefore, the results of FTIR and UV-vis confirm the increase in $\mathrm{Ce}^{3+}$ concentration in ceria slurry via UV irradiation and the photo-oxidative degradation of polyacids. Figure $2 \mathrm{~d}$ shows that upon addition of PAA and PMA to ceria slurry, the concentration of dissolved oxygen increased slightly up to $10 \mathrm{~min}$ of UV irradiation, but decreased gradually with further increase in time. The decrease in the dissolved oxygen is a clear outcome of the photo-oxidation of polyacids. This was the reason for the addition of polyacids to form additional oxygen vacancies on the surface of the ceria particle. In this experiment, PAA consumed more dissolved oxygen for photo-oxidative degradation than that of PMA. From the results of the UV irradiation, the dissolved oxygen in the ceria slurry decreased up to $\sim 23 \%$. The concentration of dissolved oxygen was not lower than $6.3 \mathrm{mg} / \mathrm{L}$ because the chamber for UV treatment on slurry was not airtight. The formation of oxygen 
(a)



(c)

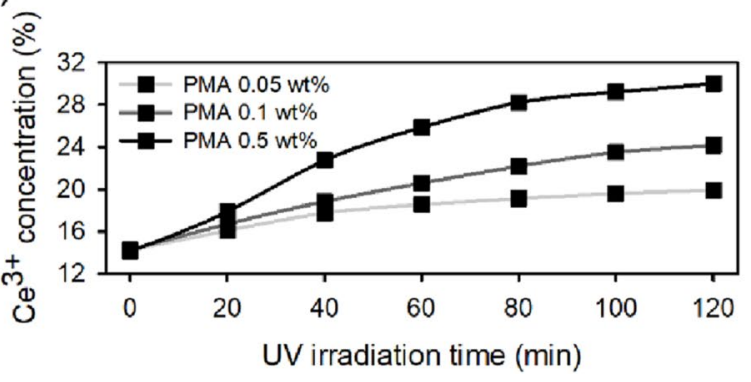

(b)

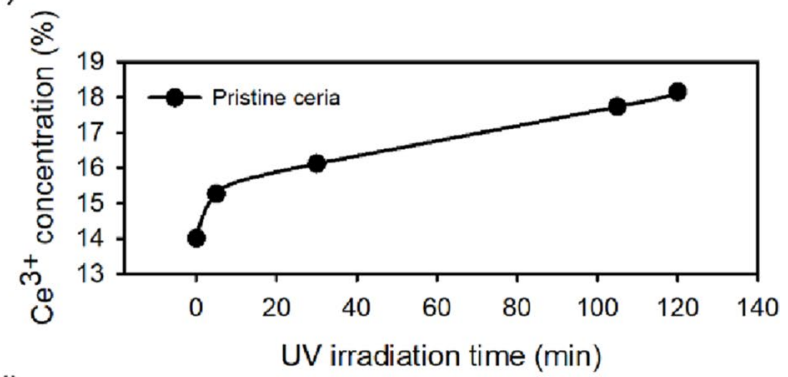

(d)

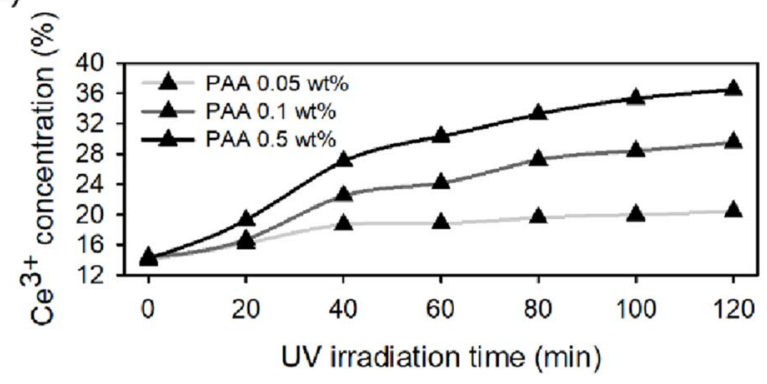

Figure 3. (a) XPS spectra of the $\mathrm{Ce} 3 d$ peaks of the $\mathrm{CeO}_{2}$ and an increase in the concentration of $\mathrm{Ce}^{3+}$ ions according to (b) UV irradiation and photo-oxidative degradation of (c) PMA and (d) PAA at different concentrations.

vacancy via UV irradiation was directly related to the reduction of the surrounding $\mathrm{Ce}^{4+}$ ions, and the reduction of $\mathrm{CeO}_{2}$ was identified by measuring the $\mathrm{Ce}^{3+}$ concentration using XPS. Figure 3 a shows the XPS Ce $3 d$ spectra of ceria nanoparticles. Ten peaks were observed in the Ce $3 d$ valence band, among which the identified peaks were labeled $\mathrm{u}_{0}, \mathrm{u}, \mathrm{u}^{\prime}, \mathrm{u}^{\prime \prime}$, and $\mathrm{u}^{\prime \prime \prime}$, corresponding to Ce $3 d 3 / 2$, and $\mathrm{v}_{0}, \mathrm{v}, \mathrm{v}^{\prime}, \mathrm{v}^{\prime \prime}$, and $\mathrm{v}^{\prime \prime \prime}$, corresponding to Ce $3 d 5 / 2$. Among these peaks, $\mathrm{u}^{\prime}, \mathrm{u}_{0}, \mathrm{v}^{\prime}$, and $\mathrm{v}_{0}$ correspond to $\mathrm{Ce}^{3+}$ ions, while the others correspond to Ce $\mathrm{e}^{4+}$ ions. Based on these results, the $\mathrm{Ce}^{3+}$ concentration was determined by the ratio of $\mathrm{Ce}^{3+}$ to the total as shown by the following Equation (10-12) $)^{55,56}$.

$$
\begin{gathered}
\text { Area }\left(\mathrm{Ce}^{3+}\right)=A\left(u^{\prime}\right)+A(u 0)+A\left(v^{\prime}\right)+A(v 0) \\
\operatorname{Area}\left(C e^{4+}\right)=A(u)+A\left(u^{\prime \prime}\right)+A\left(u^{\prime \prime \prime}\right)+A(v)+A\left(v^{\prime \prime}\right)+A\left(v^{\prime \prime \prime}\right) \\
\%\left(C e^{3+}\right)=\operatorname{Area}\left(C e^{3+}\right) /\left[\text { Area }\left(C e^{3+}\right)+\operatorname{Area}\left(C e^{4+}\right)\right]
\end{gathered}
$$

The concentration of $\mathrm{Ce}^{3+}$ ions in ceria particles increased from $14 \%$ to $18.1 \%$ with increasing UV irradiation time, as shown in Fig. 3b. Due to the formation of oxygen vacancies on the surface of the ceria particles by UV light, $\mathrm{Ce}^{4+}$ ion was reduced to $\mathrm{Ce}^{3+}$. However, the rate of reduction was inhibited by dissolved oxygen. Figure $3 \mathrm{c}$, $\mathrm{d}$ shows an increase in $\mathrm{Ce}^{3+}$ concentration with increasing concentrations of PMA and PAA additives and increasing UV irradiation time. In this connection, XPS spectra of each prepared slurry before and after UV irradiation for 120 min were shown in Figure S3 and the concentration of $\mathrm{Ce}^{3+}$ was listed in Table S3. The addition of polyacids only hardly affects the concentration of $\mathrm{Ce}^{3+}$ ions. However, in environments given UV light, the formation of oxygen vacancies on the ceria particles via photo-oxidation of polyacids was promoted, showing a high rate of increase in the concentration of $\mathrm{Ce}^{3+}$ ions. The increase in the addition of polyacids allowed the reduction of ceria with higher efficiency, and the PAA had a significant effect on reducing ceria particles than that of PMA. It was observed that photo-degraded PAA consumes more oxygen and has a higher absorbance than that of PMA at the same concentration. This indicates that photo-oxidative degradation might be more susceptible to UV light than that of PMA. Therefore, at the same concentration, PAA always showed a higher reduction efficiency than that of PMA. When $1 \mathrm{wt}$.\% PAA was added and UV irradiation was continued for 120 min, the concentration of $\mathrm{Ce}^{3+}$ ions increased from $14.2 \%$ to $36.5 \%$.

The trivalent state of cerium promotes $\mathrm{Ce}-\mathrm{O}$-Si bonding with an enhancement of the interaction between ceria particles and silicon dioxide wafer. Since the formation of Ce-O-Si bonding in an oxide CMP using ceria abrasives is directly related to the material removal rate, high concentrations of $\mathrm{Ce}^{3+}$ ions can provide high CMP performance ${ }^{18,21,57}$. Figure 4 shows CMP performance including the removal rate and finished surface roughness of the oxide film using photo-reduced ceria nanoparticles according to UV irradiation time. The CMP results show an increased removal rate upon UV irradiation on pristine ceria slurry. When UV light was irradiated for $120 \mathrm{~min}$, the removal rate was $2973.05 \AA / \mathrm{min}$, which was an increase of $20 \%$ compared with that of the removal rate of oxide film using pristine ceria slurry. In general, the addition of a surfactant can lead to a decrease in 
(a)


$\mathrm{nm}$

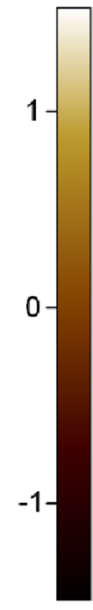

(c)

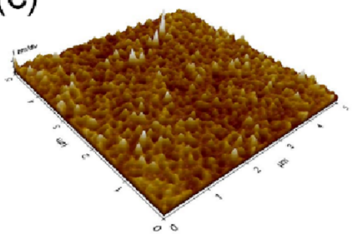

$\mathrm{Ra}=0.238 \mathrm{~nm}$

(e)

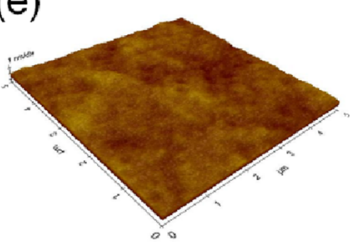

$\mathrm{Ra}=0.131 \mathrm{~nm}$

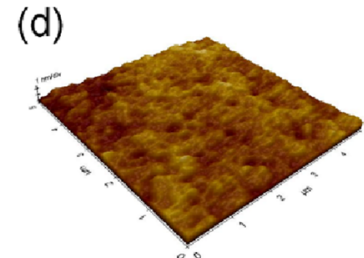

(d)

$\mathrm{Ra}=0.203 \mathrm{~nm}$

(f)

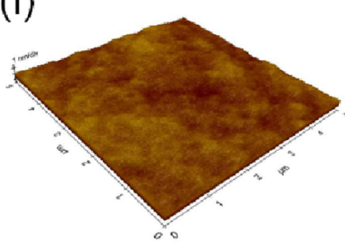

$\mathrm{Ra}=0.124 \mathrm{~nm}$

Figure 4. MRR of oxide wafer according to UV irradiation time with varying the concentration of polyacids; (a) PMA and (b) PAA and following averaged surface roughness $\left(\mathrm{R}_{\mathrm{a}}\right)$ of $\mathrm{SiO}_{2}$ wafer; (c) before polished, (d) polished by pristine ceria slurry, (e) polished by UV irradiated slurry with $0.5 \mathrm{wt} . \%$ of PAA for $1 \mathrm{~h}$ and (f) for $2 \mathrm{~h}$.

$M_{R R}{ }^{58}$. Surfactants are adsorbed on particles or wafers to form a passivation layer and reduce MRR by inhibiting mechanical interaction between abrasives and the surface of a wafer. The MRR was hindered by an increase in molecular weight and concentration of surfactants ${ }^{59-61}$. PAA used in this experiment are anionic surfactants and have negative potential in hydrated states. Therefore, it can be easily adsorbed to ceria abrasives exhibiting positive potential, especially in neutral or acidic media, which can interfere with polishing performance ${ }^{62}$. However, in this experiment, the ceria slurry was prepared with a $\mathrm{pH}$ of 9 to avoid the problem of adsorption. Since the particles have a negative charge in the basic medium, interference due to an addition of the polyacids during the polishing process was as small as to be insignificant. Therefore, the removal rate was maintained or was slightly decreased when up to $0.5 \mathrm{wt}$ \% of polyacids were added. However, when UV light was irradiated, a higher rate of increase in MRR was obtained than that of pristine ceria slurry. With increasing duration of irradiation, it was observed that a higher removal rate as much as an increase in $\mathrm{Ce}^{3+}$ concentration, also a higher MRR was obtained according to the addition of a higher concentration of polyacids. As a result, when UV light was irradiated on ceria slurry containing $0.5 \mathrm{wt} . \%$ of polyacids for $120 \mathrm{~min}$, the material removal rate was increased up to $3977.73 \AA /$ min with PMA and up to $4514.05 \AA$ /min with PAA, as shown in Fig. $4 \mathrm{a}$, b. The reactivities of ceria abrasives were enhanced via photo-oxidative degradation of polyacids, resulting in increased CMP performance of ceria slurry by up to $87 \%$. Figure $4 \mathrm{c}-\mathrm{f}$ shows the AFM images of the surface roughness of the polished wafer. A smooth surface of the polished wafer was obtained with an increase in the time of UV irradiation on the fabricated slurry. The surface roughness of the wafer after CMP is closely related to the dispersibility of the abrasives, which will be described in detail in the following sections. As a result, the performance of high removal rate and smooth surface indicate that the performance of ceria slurry with polyacids was significantly improved through UV irradiation.

Dispersibility improvement through photo-oxidation. Anionic polymers such as polyacids have been used to disperse positively charged ceria particles ${ }^{5,8}$. When polyacids were added to the slurry, the $\mathrm{COOH}$ groups of PAA were deprotonated to negatively charged COO- groups at $\mathrm{pH}$ above its $\mathrm{pK}_{\mathrm{a}}$ of 4.5 and were adsorbed on the positively charged ceria surface via electrostatic attractive interaction and hydrogen bonding, which increased the electrostatic repulsion as well as a steric hindrance between the ceria particles.

However, PAA-coated ceria particles are known to undergo transitions of bridging agglomeration-stableflocculation depending on their physicochemical conditions such as $\mathrm{pH}$, ionic strength, temperature, and concentration ${ }^{63}$. In this case, the polymer interferes with the interaction among particles, so that they do not come into direct contact with each other, however, it is difficult to confirm that the dispersibility of a solution is good due to the bridging agglomeration of nanoparticles by polymers ${ }^{35,64}$. In this experiment, the ceria particles have negative potential because the $\mathrm{pH}$ of the slurry was adjusted to $9^{63}$. The repulsive force between a polymer and a particle surface becomes strong with increasing $\mathrm{pH}$, which hinders the adsorption of polyacids on the ceria surface. Therefore, in solutions with $\mathrm{pH} 9$, only a small amount of polyacid is adsorbed on the partially positively charged surface of the ceria particle or floating in the solution as a polymer chain state as shown in Figure $\mathrm{S} 4{ }^{65-67}$. The polymer chain which has the same charged state as colloids could prohibit an agglomeration of particles through electrical repulsion force and steric hindrance ${ }^{31,62}$. Improvements in the dispersibility of a slurry can be defined in terms of three criteria: reductions in the mean diameter of particles, the size distribution width of particles, and the polydispersity index. The polydispersity index is a measure of the heterogeneity of a sample in terms of size ${ }^{68}$. 


\begin{tabular}{|c|c|c|c|c|c|c|c|}
\hline \multirow[b]{2}{*}{ Cumulant size } & \multirow[b]{2}{*}{ Pristine ceria } & \multicolumn{4}{|c|}{ PAA concentration (wt.\%) } & \multicolumn{2}{|c|}{$\begin{array}{l}\text { PAA 0.1 } \\
\text { wt.\% + UV } \\
\text { irradiation } \\
\text { time (min) }\end{array}$} \\
\hline & & 0.05 & 0.1 & 0.25 & 0.5 & 60 & 120 \\
\hline $\mathrm{D} 10(\mathrm{~nm})$ & 72.7 & 75.8 & 71.9 & 72.5 & 58.8 & 51.9 & 48.4 \\
\hline D50 (nm) & 115 & 102 & 96.5 & 96.3 & 83.6 & 66.4 & 61.7 \\
\hline D90 (nm) & 213.2 & 151.3 & 146.1 & 140.1 & 137.3 & 90.8 & 84.3 \\
\hline PI & 0.206 & 0.077 & 0.098 & 0.097 & 0.086 & 0.085 & 0.060 \\
\hline
\end{tabular}

Table 1. The particle size distribution and polydispersity index of ceria slurry according to the concentration of PAA and the duration of UV irradiation.

(a)

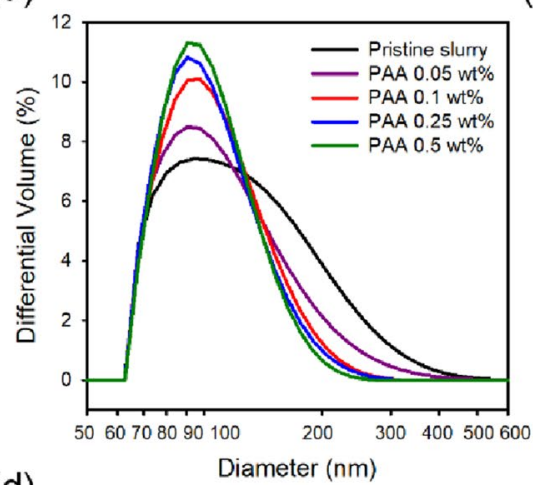

(d)

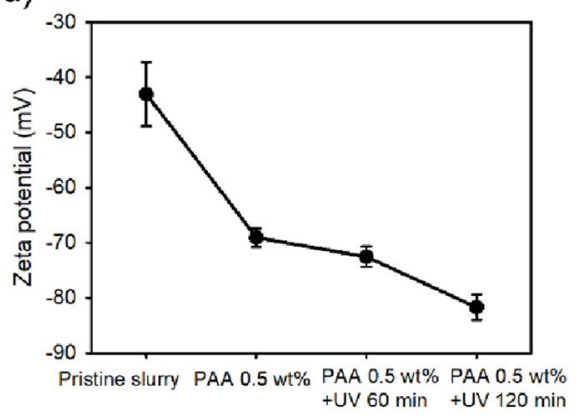

(b)
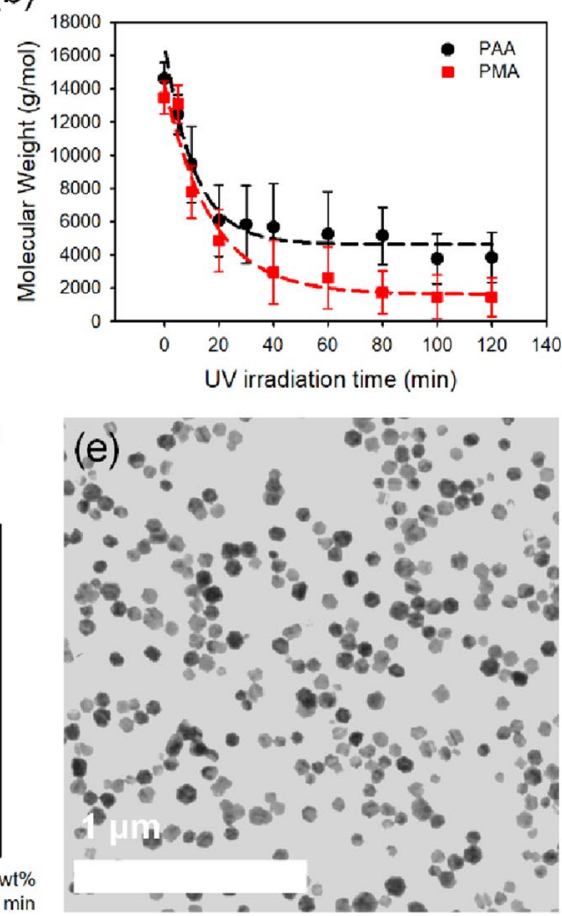

(c)
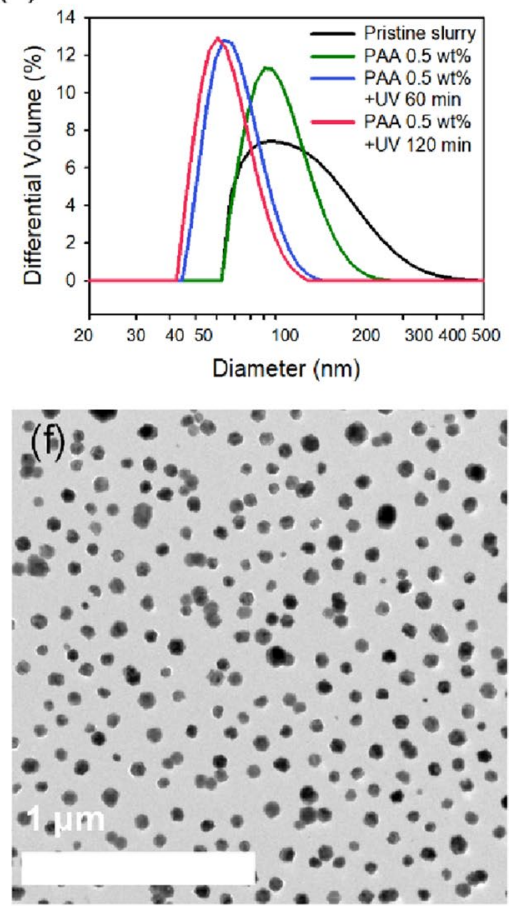

Figure 5. (a) Particle size distribution of ceria slurry according to the addition of PAA with various concentrations. The improvement of dispersity through photo-oxidative degradation of polyacids was verified by measuring the changes in (b) molecular weight of poly acids due to the photo-oxidative degradation of polyacids, (c) particle size distribution, and (d) zeta potential of ceria slurry according to UV irradiation time with fixed PAA concentration of $0.5 \mathrm{wt}$.\%. TEM images of (e) pristine ceria slurry and (f) UV irradiated ceria slurry with polyacids confirms the dispersity of the slurry.

Table 1 lists the mean diameter of ceria particles according to the addition of PAA with various concentrations. There were no significant changes in median diameter (D50) of ceria particles with increasing polymer concentration. However, the decrease in the width of size distribution as shown in Figure $5 \mathrm{a}$ and the polydispersity index listed in Table 1 indicate the positive effects of polyacids in improving the dispersity of a slurry. Pristine ceria slurry has low dispersibility, so it has a wide particle size distribution and a large median diameter. The dispersity of pristine ceria slurry was improved with an increase in the concentration of polyacids by enhancing electrostatic repulsion and preventing particle agglomeration ${ }^{31,32}$. In addition, the dispersion effect increases with decreasing length of the polymer chain. The magnitude of the repulsive contribution from depletion effects increases as the concentration increases but decreases as the chain length increases ${ }^{69-71}$. Surfactants with larger molecular weight could not freely move around nanoparticles and effectively adsorb on their surface so that the dispersibility of the slurry couldn't be improved efficiently. As UV irradiation time increases, polymers consume oxygen and undergo photo-oxidative degradation, resulting in a decrease in molecular weight as shown in Fig. 5b. Since polymers with shorter chain length tend to reside in solutions compared with polymers with longer chains, bridging agglomeration was inhibited and the free volume between particles and polymers was reduced to improve the stability of nanoparticles ${ }^{72}$. Furthermore, the presence of polymer chains of multiple lengths can improve dispersibility. Photo-oxidized polymers have a wider distribution of molecular weight, although the average molecular weight 
distribution is lower than that of the conventional refined molecular weight distribution. Therefore, the adsorbed polymer forms a rough surfactant layer on the surface of the particle. Consequently, the dispersity of ceria slurry was improved with increasing UV irradiation time due to photo-oxidative degradation of polyacids as shown in Fig. 5c. The rough surfactant layer is responsible for the improved dispersion stability through the enhanced solvent-surfactant interaction and decreased interactions between the interparticle surfactants ${ }^{73,74}$. Changes in zeta potential over chain length also played a significant role in the dispersibility of particles. Figure $5 \mathrm{~d}$ shows the variation in the zeta potential of ceria slurry containing $0.5 \mathrm{wt}$ \% of PAA with UV irradiation time. The zeta potential of pristine ceria was $-43.07 \mathrm{mV}$, and the electrokinetic potential was enhanced to $-82.73 \mathrm{mV}$ with increasing UV irradiation time. The chain expansion occurs due to the reactive electronic interaction caused by negative potential between particles and adsorbed polymers in a solution with a $\mathrm{pH}$ of 9 . This enhances the shear plane potential, thus achieving a high absolute value of zeta potential. Therefore, the electrical repulsion force between particles and polymers increases, improving dispersibility, as UV irradiation time increases. TEM images shown in Fig. 5e, f confirmed that the dispersibility of ceria nanoparticles was enhanced upon the addition of PAA with UV irradiation for $2 \mathrm{~h}$.

The dispersity of abrasive is closely related to the surface roughness of polished wafers ${ }^{75-77}$. Since a slurry with low dispersity forms a significant amount of agglomerated large particles, it is considerably affected by mechani$\mathrm{cal}$ abrasion and the surface of the polished wafer becomes rough. Based on the fully plastic deformation and the abrasive indentation assumption, the indentation depth $(\Delta)$ of the spherical abrasives into the wafer can be derived as follows ${ }^{78}$

$$
\Delta=\frac{2 F}{\pi x H_{w}}
$$

where $x$ is the diameter of the abrasives and $H_{w}$ is the hardness of the wafer. $F$ is the force applied on a single abrasive, which can be calculated as follows.

$$
F=0.25 \pi P_{c} x^{2}
$$

where $P_{c}$ is the contact pressure from a specified contact area of the pad asperity. According to Eqs. $(13,14)$, the indentation depth is proportional to the diameter of abrasives. Because the indented mark is the result of abrasion on the surface of the wafer by the particles, a decrease in the particle size indicates a decrease in the indentation depth, which in turn leads to reduced surface roughness. Yang et al. also verified an increase in the surface roughness as a function of an increase in the size of the ceria nanoparticles ${ }^{75}$. In this experiment, the dispersity of ceria slurry was improved with the addition of polyacids and their photo-oxidative degradation by irradiating UV light. After UV treatment with PAA, the D50 of the particle size distribution decreased from 115 $\mathrm{nm}$ to $61.7 \mathrm{~nm}$. As a result, a smooth surface of polished wafer could be obtained with an increase in the UV irradiation time as shown in Fig. 4c-f. The average roughness decreased from $0.238 \mathrm{~nm}$ to $0.124 \mathrm{~nm}$ when the UV light was irradiated on the ceria slurry for $2 \mathrm{~h}$. A smooth surface was obtained due to the photo-oxidative degradation of polyacids, although the MRR drastically increased.

\section{Conclusion}

In this study, photoreactions of ceria and polyacids were performed in a basic solution to improve the CMP performance of ceria slurry. UV irradiation on ceria lowers the oxygen vacancy formation energy, increasing the concentration of $\mathrm{Ce}^{3+}$ ions on the surface of the ceria nanoparticles. Since $\mathrm{Ce}^{3+}$ ion is an active site involved in material removal by forming a Ce-O-Si bond with an oxide wafer, an increase in $\mathrm{Ce}^{3+}$ concentration leads to an increase in MRR. Simultaneously, the photo-oxidative degradation reaction of polyacids contributed to the improvement of the polishing performance of the ceria abrasives in two ways. First, the degradation of polymers by UV light significantly affected the formation of $\mathrm{Ce}^{3+}$ ions on the surface of the ceria particles by reducing the contents of dissolved oxygen, which inhibited the reoxidation of ceria particles and facilitated the formation of oxygen vacancies, resulting in a significant improvement in MRR. The MRR increased with increasing polyacid concentration to $0.5 \mathrm{wt}$.\% and increasing duration of UV irradiation time to $2 \mathrm{~h}$. Second, during the photodegradation process, the molecular weight of polyacids was reduced and shortened polymer chains reside in the solution to enhance dispersity of slurry by strengthening the electrostatic repulsive force between particles. The ceria slurry, which has improved dispersibility due to the degradation of polyacids, was used to polish the wafer surface comparatively smoothly, resulting in low average roughness. Therefore, the CMP performance, in terms of removal rate and surface roughness, was significantly improved by photo-reduction of ceria and photooxidative degradation of polyacids induced by UV light irradiation.

\section{Methods}

UV irradiation on ceria slurries. In this experiment, $60-\mathrm{nm}$ commercial ceria abrasive was used to polish the oxide film. The nanoparticles were diluted in deionized (DI) water to obtain a concentration of $0.5 \mathrm{wt} \%$ of solid contents. Two types of polyacid solutions, containing either PAA (Wako, Japan) or PMA (Sigma Aldrich, USA) (average molecular weight $10,000 \mathrm{~g} / \mathrm{mol}$ ), were used to achieve particle dispersion and photo-oxidation effects. Both polymers have a similar structure and are anionic surfactants that exhibit a negative potential when dissolved in water. In addition, since the ceria particles have a negative potential in a basic solution, $\mathrm{KOH}$ was added to the ceria slurry to obtain a $\mathrm{pH}$ of 9 , thus preventing the adsorption of polyacids on particles and inhibiting interactions between particles and the wafer surface. Moreover, the polymer concentration was maintained at a level lower than that of the solid contents to prevent the polymer from impeding the mechanical abrasion between the abrasives and the wafer. 


\begin{tabular}{|l|l|}
\hline Parameter & Condition \\
\hline Material & $1-\mu \mathrm{m}$-thick $\mathrm{SiO}_{2}$ film on four-inch wafer \\
\hline Pad & $\mathrm{IC} 1010 / \mathrm{Suba} \mathrm{IV}$ \\
\hline Down pressure on the wafer & $4 \mathrm{psi}$ \\
\hline Down force on conditioner & $3 \mathrm{kgf}$ \\
\hline Pad rotation speed & $93 \mathrm{rpm}$ \\
\hline Wafer rotation speed & $87 \mathrm{rpm}$ \\
\hline Slurry flow rate & $120 \mathrm{~mL} / \mathrm{min}$ \\
\hline Process time & $1 \mathrm{~min}$ \\
\hline
\end{tabular}

Table 2. CMP condition.

A closed chamber was fabricated to ensure effective irradiation of UV light on the ceria slurry. An Al foil was used to cover the inner wall of the chamber to prevent leakage of light and increase the efficiency of irradiation. A magnetic stirrer was installed at the bottom of the chamber, which stirred the ceria slurry at $400 \mathrm{rpm}$ to ensure uniform UV light exposure. A UV light source was installed on the wall above the chamber. It was fixed at a distance of $3.5 \mathrm{~cm}$ apart from the surface when $500 \mathrm{~mL}$ of the slurry was placed in the beaker. The wavelength of the light generated by the UV-light source was $254 \mathrm{~nm}$ at $6 \mathrm{~W}$, and the intensity of UV light on the surface of the solution was $489 \mathrm{~mW} / \mathrm{cm}^{225}$. Since the light of wavelength lower than $254 \mathrm{~nm}$ can provide photon energy greater than that of the bandgap of the ceria particles $\left(3-3.6 \mathrm{eV}^{79}\right)$, the separation of the electron-hole pair from the valance band of ceria decreases the oxygen vacancy formation energy from $1.16 \mathrm{eV}$ to $-0.64 \mathrm{eV}$ in the presence of UV light ${ }^{25}$. With the lowered oxygen vacancy formation energy, the electrons and holes generated from the $\mathrm{UV}$ irradiation reduce $\mathrm{Ce}^{4+}$ to $\mathrm{Ce}^{3+}$ and the holes oxidize $\mathrm{O}^{2-}$ anions ${ }^{24,29}$. Additionally, it can provide sufficient energy to generate chain scission of polymers.

Confirmation of photo-oxidative degradation of polyacids. Polyacids under the exposure of UV light in the chamber form chromophores such as ethylene bonds and carbonyl groups, during photo-degradation. The change in the intensity of absorbance depends upon the concentration of chromophores. The change in the absorption spectra was measured by UV-visible spectroscopy (UV-3600, SHIMADZU, Japan). The photo-oxidation processes were confirmed by Fourier-transform infrared (FTIR) spectroscopy (IFS-66/2, Bruker, USA). The total carbonyl group contents were calculated from the area of the peaks in the range of $1600-1800 \mathrm{~cm}^{-1}$. The photo-oxidative degradation process of polyacids in ceria slurry was also confirmed by UV-visible spectroscopy and FTIR spectroscopy. Moreover, the decrease in the concentration of dissolved oxygen due to photo-oxidation of polyacids was measured in real-time using a dissolved oxygen meter with a microsensor (Oxyscan 300, UMS $\mathrm{GmbH} \& \mathrm{CO}$. KG, Germany). It was also confirmed that the photo-oxidative degradation caused chain scission in polyacids by measuring the changes in the molecular weight of polyacids through a molecular weight analyzer with static light scattering (SLS) method (ELSZ-2000, Otsuka Electronics Co.). The photo-reduction of ceria particles enhanced by photo-oxidation of polymer can be verified as a change in the concentration of $\mathrm{Ce}^{3+}$ ions in the ceria particles. The concentration of $\mathrm{Ce}^{3+}$ ions, which is the final product affecting CMP performance, was determined by X-ray photoelectron spectroscopy (XPS; ESCALAB 250, Thermo Fisher, USA).

Chemical mechanical polishing (CMP). For the CMP process, the oxide wafers were polished on a rotary-type CMP machine (Poly-400, G\&P Technology, Korea) with a polyurethane polishing pad (IC1010, Dupont, USA). The polishing pad was conditioned before polishing for $30 \mathrm{~min}$ to obtain a uniform surface. The mechanical conditioning process was performed simultaneously while polishing the wafer with a load force of $3 \mathrm{kgf}$ to ensure that the pores are not clogged and to prevent changes in CMP performance. CMP slurry was prepared by mixing ceria nanoparticles, polyacids, and $\mathrm{pH}$ adjuster with DI water. The fabricated slurry was fixed at 0.5 wt.\% of solid contents and $\mathrm{pH} 9$, and the initial dissolved oxygen is $8.1 \mathrm{mg} / \mathrm{L}$ on average. The prepared CMP slurry is irradiated to UV light for a specific time in the chamber with continuous stirring and then directly supplied to the CMP process. The slurry is supplied directly from the chamber to the CMP equipment still under UV irradiation. The load pressure applied on the wafer was 3 psi. The rotation speed of the platen was $93 \mathrm{rpm}$ and the rotation speed of the wafer head was $87 \mathrm{rpm}$. Table 2 provides additional information about the experimental conditions for polishing. The material removal rate (MRR) of the polished oxide film was obtained by measuring the difference between the thickness of the oxide film before and after CMP using a reflectometer (ST5030-SL, K-MAC Co., Korea). Finally, the final surface of the polished wafer was observed using atomic force spectroscopy (AFM; NX10, Park systems, Korea).

Confirmation of dispersity in ceria slurry. The dispersion of nano-abrasives in the slurry is an important factor that affects the CMP performance, in terms of surface defects including surface roughness or scratches ${ }^{80}$. The dispersity of particles can be determined from changes in the average particle size and the width of particle size distribution ${ }^{65,81}$. A particle sizer was used to measure the mean particle size and size distribution by the dynamic light scattering (DLS) method. The addition of polyacids and the effect of photo-degraded polyacids on the dispersion of the ceria particles were confirmed using the D10, D50, and D90 values of the cumulative particle size to quantify both particle size and size distribution. Furthermore, the changes in the zeta potential of 
the ceria slurry due to the decomposition and ionization of polymers were measured. Finally, the agglomeration of particles according to dispersibility was visually identified using transmission electron microscopy (TEM; JEM-2100F, JEOL, Japan).

\section{Data availability}

All relevant data are within the paper.

Received: 6 August 2021; Accepted: 6 December 2021

Published online: 31 January 2022

\section{References}

1. Urban, N. D., Dickmann, D., Her, B. \& Santora, B. Mechanisms and development of ceria-based, fast oxide slurries. ECS Trans. 72, 37-42 (2016)

2. Li, T. C. et al. CMP solutions for 3D-NAND staircase CMP. In 2015 International on Conference Planarization/CMP Technology. ICPT 2015 5-7 (2016).

3. Wonjoo, K. et al. Multi-layered vertical gate NAND flash overcoming stacking limit for terabit density storage. In Digest of Technical Papers-Symposium on VLSI Technology 188-189 (2009).

4. Dandu, P. R. V., Peethala, B. C. \& Babu, S. V. Role of different additives on silicon dioxide film removal rate during chemical mechanical polishing using ceria-based dispersions. J. Electrochem. Soc. 157, H869 (2010).

5. Kurokawa, S., Toyama, T., Hayashi, T., Suda, E. \& Tokuda, J. Controllable CMP of oxide film by using colloidal ceria slurry. In ICPT 2017-International Conference on Planarization/CMP Technology 177-182 (2017).

6. Cook, L. M. Chemical processes in glass polishing. J. Non Cryst. Solids 120, 152-171 (1990).

7. Hoshino, T., Kurata, Y., Terasaki, Y. \& Susa, K. Mechanism of polishing of $\mathrm{SiO}_{2}$ films by $\mathrm{CeO}_{2}$ particles. J. Non Cryst. Solids 283, $129-136(2001)$.

8. Kelsall, A. Cerium oxide as a route to acid free polishing. Glass Technol. 39, 6-9 (1998).

9. Sabia, R. \& Stevens, H. J. Performance characterization of cerium oxide abrasives for chemical-mechanical polishing of glass. Mach. Sci. Technol. 4, 235-251. https://doi.org/10.1080/10940340008945708 (2007).

10. Choudhury, B., Chetri, P. \& Choudhury, A. Oxygen defects and formation of $\mathrm{Ce}^{3+}$ affecting the photocatalytic performance of $\mathrm{CeO}_{2}$ nanoparticles. RSC Adv. 4, 4663-4671 (2014).

11. Campbell, C. T. \& Peden, C. H. F. Oxygen vacancies and catalysis on ceria surfaces. Science 309, 713-714 (2005).

12. Xu, J. et al. Size dependent oxygen buffering capacity of ceria nanocrystals. Chem. Commun. 46, 1887-1889 (2010).

13. Dutta, P. et al. Concentration of $\mathrm{Ce}^{3+}$ and oxygen vacancies in cerium oxide nanoparticles. Chem. Mater. 18, 5144-5146 (2006).

14. Esch, F. et al. Chemistry: Electron localization determines defect formation on ceria substrates. Science 309, $752-755$ (2005).

15. Binet, C., Badri, A. \& Lavalley, J. C. A spectroscopic characterization of the reduction of ceria from electronic transitions of intrinsic point defects. J. Phys. Chem. 98, 6392-6398 (1994).

16. Seo, J. et al. Role of the oxidation state of cerium on the ceria surfaces for silicate adsorption. Appl. Surf. Sci. 389, 311-315 (2016).

17. Sahir, S. et al. Investigation of the effect of different cleaning forces on Ce-O-Si bonding during oxide post-CMP cleaning. Appl. Surf. Sci. 545, 149035 (2021).

18. Myong, K. K. et al. Direct and quantitative study of ceria- $\mathrm{SiO}_{2}$ interaction depending on $\mathrm{Ce}^{3+}$ concentration for chemical mechanical planarization (CMP) cleaning. Mater. Sci. Semicond. Process. 122, 105500 (2021).

19. Doi, H., Suzuki, M. \& Kinuta, K. Effects of $\mathrm{Ce}^{3+}$ on removal rate of ceria slurries in chemical mechanical polishing for $\mathrm{SiO}_{2}$. In ICPT 2014-Proceedings of International Conference on Planarization/CMP Technology. 2014 194-198 (2015) https://doi.org/10. 1109/ICPT.2014.7017278.

20. Netzband, C. M. \& Dunn, K. Controlling the cerium oxidation state during silicon oxide CMP to improve material removal rate and roughness. ECS J. Solid State Sci. Technol. 9, 044001 (2020).

21. Kim, K., Yi, D. K. \& Paik, U. Increase in $\mathrm{Ce}^{3+}$ concentration of ceria nanoparticles for high removal rate of $\mathrm{SiO}_{2}$ in chemical mechanical planarization. ECS J. Solid State Sci. Technol. 6, P681-P685 (2017).

22. Wang, L., Zhang, K., Song, Z. \& Feng, S. Ceria concentration effect on chemical mechanical polishing of optical glass. Appl. Surf. Sci. 253, 4951-4954 (2007).

23. Singhania, A. \& Bhaskarwar, A. N. Effect of rare earth (RE - La, Pr, Nd) metal-doped ceria nanoparticles on catalytic hydrogen iodide decomposition for hydrogen production. Int. J. Hydrogen Energy 43, 4818-4825 (2018).

24. Wu, T. S. et al. Enhancement of catalytic activity by UV-light irradiation in $\mathrm{CeO}_{2}$ nanocrystals. Sci. Rep. 9, 2-8 (2019).

25. Kim, E. et al. Improvement of oxide removal rate in chemical mechanical polishing by forming oxygen vacancy in ceria abrasives via ultraviolet irradiation. Mater. Chem. Phys. https://doi.org/10.1016/J.MATCHEMPHYS.2021.124967 (2021).

26. Schweke, D. et al. Comprehensive study of the ceria- $\mathrm{H}_{2}$ system: Effect of the reaction conditions on the reduction extent and intermediates. J. Phys. Chem. C 124, 6180-6187 (2020).

27. Morlat, S. \& Gardette, J. L. Phototransformation of water-soluble polymers. Part II: Photooxidation of poly(ethylene oxide) in aqueous solution. Polymer (Guildf). 44, 7891-7897 (2003).

28. Wu, T. S. et al. Enhancement of catalytic activity by UV-light irradiation in $\mathrm{CeO}_{2}$ nanocrystals. Sci. Rep. 9, 1-7 (2019).

29. Esmailpour, A. A., Moradi, S., Yun, J., Scott, J. \& Amal, R. Promoting surface oxygen vacancies on ceria via light pretreatment to enhance catalytic ozonation. Catal. Sci. Technol. 9, 5979-5990 (2019).

30. Schweke, D. et al. Comprehensive study of the ceria-h2system: Effect of the reaction conditions on the reduction extent and intermediates. J. Phys. Chem. C 124, 6180-6187 (2020).

31. Sehgal, A., Lalatonne, Y., Berret, J. F. \& Morvan, M. Precipitation-redispersion of cerium oxide nanoparticles with poly (acrylic acid): Toward stable dispersions. Langmuir 21, 9359-9364 (2005).

32. Faure, B. et al. Dispersion and surface functionalization of oxide nanoparticles for transparent photocatalytic and UV-protecting coatings and sunscreens. Sci. Technol. Adv. Mater. 14, 023001 (2013).

33. Kim, S. K., Lee, S., Paik, U., Katoh, T. \& Park, J. G. Influence of the electrokinetic behaviors of abrasive ceria particles and the deposited plasma-enhanced tetraethylorthosilicate and chemically vapor deposited $\mathrm{Si}_{3} \mathrm{~N}_{4}$ films in an aqueous medium on chemical mechanical planarization for shallow trench isolation. J. Mater. Res. 18, 2163-2169 (2003).

34. Takemura, A., Shida, H. \& Ikeda, M. Aqueous dispersion for chemical mechanical polishing, chemical mechanical polishing method, and kit for preparing aqueous dispersion for chemical mechanical polishing. U.S. Patent Application No. 12/295,872 (2009).

35. Paik, U. \& Park, J.-G. Nanoparticle engineering for chemical-mechanical planarization. Nanoparticle Eng. Chem. Planarization https://doi.org/10.1201/9781420059137 (2009).

36. Dunkin, I., Dunkin, I. \& Allen, N. S. Photochemistry Vol. 35 (R. Soc. Chem, 2005).

37. Rabek, J. F. Polymer Photodegradation: Mechanisms and Experimental Methods (Springer, 1995). 
38. Yousif, E. \& Haddad, R. Photodegradation and photostabilization of polymers, especially polystyrene: Review. Springerplus 2, 398 (2013).

39. Fox, R. B. Photodegradation of high polymers. Prog. Polym. Sci. 1, 45-89 (1967).

40. Fox, R. B., Isaacs, L. G., Stokes, S. \& Kagarise, R. E. Photodegradation of poly(methyl acrylate). J. Polym. Sci. Part A Gen. Pap. 2, 2085-2092 (1964).

41. Hassouna, F., Therias, S., Mailhot, G. \& Gardette, J. L. Photooxidation of poly(N-vinylpyrrolidone) (PVP) in the solid state and in aqueous solution. Polym. Degrad. Stab. 94, 2257-2266 (2009).

42. Cheremisinoff, N. P. Handbook of Polymer Science and Technology (CRC Press, 1989).

43. Ahn, K.-D. Photodegradable polymers. Korean Soc. Ind. Eng. Chem. 3, 395-406 (1992).

44. Kaczmarek, H. \& Metzler, M. The properties of poly (acrylic acid) modified with N-phenylbenzothioamide as potential drug carriers. Open Process Chem. J. 6, 1-7 (2014).

45. Tunca, A. K. Quantitative analysis of paracetamol, acetylcysteine and Guaifenesin in commercial cold medicines by UV-Vis spectroscopy. SOP Trans. Anal. Chem. 1, 40-47 (2014).

46. Jeffrey, C. Y. \& Edmund, S. Adsorption at Treated Steel-Paint Interfaces (University Camb, 2019). https://doi.org/10.17863/CAM. 46068 .

47. Louette, P., Bodino, F. \& Pireaux, J.-J. Poly(acrylic acid) (PAA) XPS reference core level and energy loss spectra. Surf. Sci. Spectra $12,22-26$ (2005).

48. Boffito, M. et al. Surface functionalization of polyurethane scaffolds mimicking the myocardial microenvironment to support cardiac primitive cells. PLoS ONE 13, 1-21 (2018).

49. Dietrich, P. M. et al. Surface analytical study of poly(acrylic acid)-grafted microparticles (beads): Characterization, chemical derivatization, and quantification of surface carboxyl groups. J. Phys. Chem. C 118, 20393-20404 (2014).

50. Tinoco, M. et al. Selective oxidation of glycerol on morphology controlled ceria nanomaterials. Catal. Sci. Technol. 9, 2328-2334 (2019).

51. Heckert, E. G., Karakoti, A. S., Seal, S. \& Self, W. T. The role of cerium redox state in the SOD mimetic activity of nanoceria. Biomaterials 29, 2705-2709 (2008).

52. Yang, Y. et al. Redox enzyme-mimicking activities of $\mathrm{CeO}_{2}$ nanostructures: Intrinsic influence of exposed facets. Sci. Rep. 6, 35344 (2016).

53. Zhu, H. et al. Catalytic oxidation of $\mathrm{CO}$ on mesoporous codoped ceria catalysts: Insights into correlation of physicochemical property and catalytic activity. J. Rare Earths 37, 961-969 (2019).

54. Singh, R. \& Singh, S. Role of phosphate on stability and catalase mimetic activity of cerium oxide nanoparticles. Colloids Surf. $B$ Biointerfaces 132, 78-84 (2015).

55. Garcia, X. et al. Ceria-based catalysts studied by near ambient pressure x-ray photoelectron spectroscopy: A review. Catalysts 10, $286(2020)$

56. Kato, S. et al. Quantitative depth profiling of $\mathrm{Ce}^{3+}$ in $\mathrm{Pt} / \mathrm{CeO}_{2}$ by in situ high-energy XPS in a hydrogen atmosphere. Phys. Chem. Chem. Phys. 17, 5078-5083 (2015).

57. Alety, S. R., Sagi, K. V. \& Babu, S. V. Role of $\mathrm{Ce}^{3+}$ Ions in Achieving High Silicon Nitride Polish Rates. ECS J. Solid State Sci. Technol. 6, P898-P903 (2017)

58. Park, J. G., Katoh, T., Lee, W. M., Jeon, H. \& Paik, U. Surfactant effect on oxide-to-nitride removal selectivity of nano-abrasive ceria slurry for chemical mechanical polishing. Jpn. J. Appl. Phys. Part 1 Regul. Pap. Short Notes Rev. Pap. 42, 5420-5425 (2003).

59. Lee, J.-D. et al. Effects of nonionic surfactants on oxide-to-polysilicon selectivity during chemical mechanical polishing. J. Electrochem. Soc. 149, G477 (2002).

60. Katoh, T., Kim, S. J., Paik, U. \& Park, J. G. Effect of slurry surfactant on nanotopography impact in chemical mechanical polishing. Jpn. J. Appl. Phys. Part 1 Regul. Pap. Short Notes Rev. Pap. 42, 5430-5432 (2003).

61. Bu, K.-H. \& Moudgil, B. M. Selective chemical mechanical polishing using surfactants. J. Electrochem. Soc. 154, H631 (2007).

62. Dylla-Spears, R. et al. Charged micelle halo mechanism for agglomeration reduction in metal oxide particle based polishing slurries. Colloids Surf. A Physicochem. Eng. Asp. 447, 32-43 (2014).

63. Seo, J. A review on chemical and mechanical phenomena at the wafer interface during chemical mechanical planarization. J. Mater. Res. https://doi.org/10.1557/jmr.2020.215 (2020).

64. Kang, H. G., Park, H. S., Paik, U. \& Park, J. G. Effects of abrasive particle size and molecular weight of poly(acrylic acid) in ceria slurry on removal selectivity of $\mathrm{SiO}_{2} / \mathrm{Si}_{3} \mathrm{~N}_{4}$ films in shallow trench isolation chemical mechanical planarization. J. Mater. Res. 22, 777-787 (2007).

65. He, H. Preparation and dispersion of nanosize ceria in high electrolyte slurry by ball-milling. Integr. Ferroelectr. 161, 36-44 (2015).

66. Boyjoo, Y., Ang, M. \& Pareek, V. Photocatalytic treatment of shower water using a pilot scale reactor. Int. J. Photoenergy 2012, 1-7 (2012).

67. Jin, L. et al. Preparation of stable and high-efficient poly(m-phenylenediamine)/reduced graphene oxide composites for hexavalent chromium removal. J. Mater. Sci. 54(1), 383-395 (2018).

68. Bhattacharjee, S. DLS and zeta potential-What they are and what they are not?. J. Control Release 235, 337-351 (2016).

69. Pacułt, J., Rams-Baron, M., Chrząszcz, B., Jachowicz, R. \& Paluch, M. Effect of polymer chain length on the physical stability of amorphous drug-polymer blends at ambient pressure. Mol. Pharm. 15, 2807-2815 (2018).

70. Kamiya, H. \& Iijima, M. Surface modification and characterization for dispersion stability of inorganic nanometer-scaled particles in liquid media. Sci. Technol. Adv. Mater. 11, 044304 (2010).

71. Yethiraj, A., Hall, C. K. \& Dickman, R. Interaction between colloids in solutions containing dissolved polymer. J. Colloid Interface Sci. 151, 102-117 (1992).

72. Koumarianos, S., Kaiyum, R., Barrett, C. J., Madras, N. \& Mermut, O. Theory and experiment of chain length effects on the adsorption of polyelectrolytes onto spherical particles: The long and the short of it. Phys. Chem. Chem. Phys. 23, 300-310 (2021).

73. Piao, L., Lee, K. H., Kwon, W. J., Kim, S. H. \& Yoon, S. The simple and facile methods to improve dispersion stability of nanoparticles: Different chain length alkylcarboxylate mixtures. J. Colloid Interface Sci. 334, 208-211 (2009).

74. Pang, Z., Zhang, J., Cao, W., Kong, X. \& Peng, X. Partitioning surface ligands on nanocrystals for maximal solubility. Nat. Commun. 10(1), 1-8 (2019).

75. Yang, J. C., Kim, H. \& Kim, T. Study of polishing characteristics of monodisperse ceria abrasive in chemical mechanical planarization. J. Electrochem. Soc. 157, H235 (2010).

76. Chen, G., Luo, G., Pan, G., Liu, Y. \& Luo, H. Influence of colloidal silica dispersion on the decrease of roughness in silicon chemical mechanical polishing. Micro Nano Lett. 11, 382-385 (2016).

77. Basim, G. B. \& Moudgil, B. M. Effect of soft agglomerates on CMP slurry performance. J. Colloid Interface Sci. 256, 137-142 (2002).

78. Luo, J. Integrated modeling of chemical mechanical planarization /polishing (CMP) for integrated circuit fabrication: From particle scale to die and wafer scales. University Calif. (1998). https://www.proquest.com/dissertations-theses/integrated-modeling-chemi cal-mechanical/docview/305342039/se-2?accountid=17077.

79. Vangelista, S. et al. Structural, chemical and optical properties of cerium dioxide film prepared by atomic layer deposition on TiN and Si substrates. Thin Solid Films 636, 78-84 (2017).

80. Babu, S. Advances in Chemical Mechanical Planarization (CMP). Advances in Chemical Mechanical Planarization (CMP) (Elsevier Inc., 2016). https://doi.org/10.1016/C2014-0-01445-1. 
81. Metin, C. O., Lake, L. W., Miranda, C. R. \& Nguyen, Q. P. Stability of aqueous silica nanoparticle dispersions. J. Nanoparticle Res. 13(2), 839-850 (2010).

\section{Acknowledgements}

This work was supported by the National Research Foundation of Korea (NRF) grant funded by the Korea government (MEST) (No. NRF-2017R1A2B3011222) and (2018R1D1A1B07040292) the MOTIE(Ministry of Trade, Industry \& Energy (No.10080545) and KSRC(Korea Semiconductor Research Consortium) support program for the development of the future semiconductor device.

\section{Author contributions}

E.K. and T.K. conceived the projects. E.K designed the experiments. E.K. and J.H. conducted the experiments. E.K. and H.S. analyzed the fundamental mechanism of chemical mechanical polishing and results. All authors discussed the results and reviewed the manuscript.

\section{Competing interests}

The authors declare no competing interests.

\section{Additional information}

Supplementary Information The online version contains supplementary material available at https://doi.org/ 10.1038/s41598-021-03866-9.

Correspondence and requests for materials should be addressed to T.K.

Reprints and permissions information is available at www.nature.com/reprints.

Publisher's note Springer Nature remains neutral with regard to jurisdictional claims in published maps and institutional affiliations.

Open Access This article is licensed under a Creative Commons Attribution 4.0 International License, which permits use, sharing, adaptation, distribution and reproduction in any medium or format, as long as you give appropriate credit to the original author(s) and the source, provide a link to the Creative Commons licence, and indicate if changes were made. The images or other third party material in this article are included in the article's Creative Commons licence, unless indicated otherwise in a credit line to the material. If material is not included in the article's Creative Commons licence and your intended use is not permitted by statutory regulation or exceeds the permitted use, you will need to obtain permission directly from the copyright holder. To view a copy of this licence, visit http://creativecommons.org/licenses/by/4.0/.

(C) The Author(s) 2022 